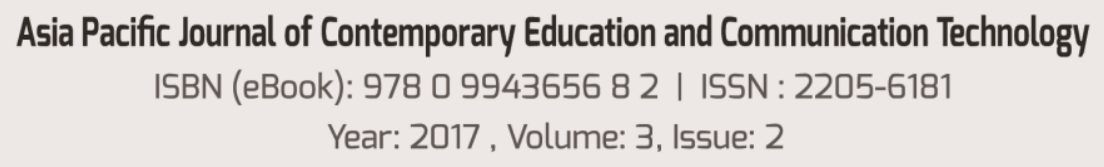

\title{
CIVILISATION ANALYSIS: UNLOCKING THE SOCIAL, CULTURAL AND POLITICAL CONTEXTS OF ARAB CIVIL SOCIETY
}

\author{
Clare Walsh \\ University of Bristol, Bristol, United Kingdom \\ Email: edcvw@bristol.ac.uk
}

\begin{abstract}
Historically, civil societies in the Arab education sector have been identified with the provision of education services for marginalised members of society, however, in the last decade, new groups have formed leading to a strengthening in the relationship between civil societies and education (Watkins, 2009). Civilisation analysis (Arnason, 2003) offers a theoretical lens in which to consider the relationship between civil society and education, looking beyond the dependency, modernisation and rentier perspectives which have been traditionally used in the analysis of Arab civil society (Crystal, 2001, 1989; Krause, 2008). This conceptual paper considers how and why civilisation analysis can be used as theoretical framework for analysis of civil society in general and Arab civil society in particular, with a specific focus on higher education. The significance of a broader theoretical approach in the analysis of Arab civil society is the ability to pursue a deeper approach to the examination of the power and impact of civil society within an educational setting.
\end{abstract}

Keywords: Arab Civil Society, Civilisation Analysis, Higher Education.

\section{Introduction and purpose}

Arab civil society, in concept and structure, is unique and complex to comprehend (Bardhan \& Wood, 2015). Civil society and how it is defined, in an Arab context, needs to be studied from within its own social, cultural and political contexts, all of which are grounded within their own historical trajectory (Armstrong \& Gilson, 2011). Traditional Western analysis of civil society separates it from, and places it in opposition to the holders of power, creating a space that is defined in a euro-centric manner. Western analysis of civil society, when transposed on the Arab region, recognises a modernity only in terms of its resemblance to the West and as noted by Armstrong \& Gilson (2011:6) the objectives of civil societies in nonWestern states are different from those of the West. A broader theoretical approach is needed in order to comprehend the concept and structure of Arab civil society, allowing for a deeper analytical approach which may be significant in terms of understanding civil societies and their ability to influence change for example. Secondly, it is recognised that civil society can develop in different ways. Factors such as key symbols can be ascertained and with those symbols important "religious, ideological, primordial and historical aspects" (Eisenstadt, 2002: 159) can to be considered. Furthermore, the development of civil society can also evolve in different ways depending on inter-related aspects such as how political order is conceived, and the relationship of political order to other social orders; how political authority and its accountability is conceived; as well as the conception of the subject; and the "modes of centre-periphery relations" (Eisenstadt, 2002:159). If these factors are recognised as influencing the development and structure of civil society, then how can they be accounted for without reverting to a Western orientated framework of analysis? Civilisation analysis (Arnason, 2003) as a theoretical framework allows the analyst the ability to consider the social, cultural and political contexts of Arab civil society thereby offering a means of accessing deeply entrenched sets of meaning and practices allowing for comparative interpretations of societal differences and a new way to understand similarity and differences, convergence and diversity in the modern world (Dale \& Robertston, 2016). 


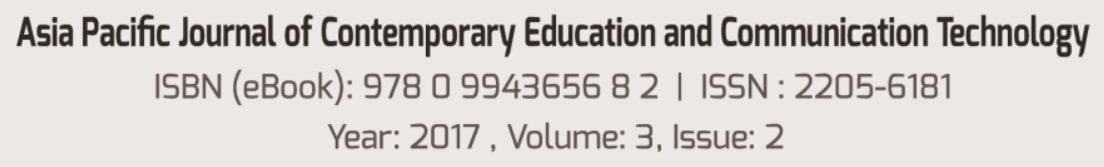

\section{Conceptual definition of civil society and its application to the Arab Gulf}

Definitions of civil society are considered complex (Armstrong \& Gilson, 2011) and are full of contradictions (Hann, 1996) with the term and concept remaining nebulous (Bardhan \& Wood, 2015). One of the more significant concerns addressed with the term is that prominent conceptualisations are reflected from a Western ethnocentricity and a European tradition, the implications of which include viewing the world from a European perspective and thereby legitimising the pre-eminence of European culture and its theories (Patel, 2013). The Western view of civil society is often orientated in democracy and understanding the ways in which democracy can be augmented, and has come to refer to a wide range of activities external to and in opposition to the state (Armstrong \& Gilson, 2011). However, as noted by Armstrong \& Gilson, (2009, p. 6) the objectives of civil societies in non-Western states are different from those pursuing democratic change, therefore, civil society and how is it is defined has to be understood "within its own historical trajectory and studied within specific socio-cultural and political contexts". Bardhan \& Wood (2015) argue that the concept of civil society is not strictly emblematic of the West, but equally, the Western paradigm of civil society cannot adequately define Arab civic culture. Arab civil society should be approached in a cultural and context-specific manner as "civil society in the Arab region is characterised by its distinctive origins, a unique trajectory of development and is idiosyncratic in its nature, scope and functions (Bardhan \& Wood, 2015, p. 119)”.

The literature on Arab civil society can be placed in three categories (Carapico, 1998) and includes the Western view that Islamic beliefs and the patriarchal tribal organisation restrict values such as tolerance and personal freedom. The political science literature takes the view that Arab states block civil society and civic participation, which is achieved through distribution of rents in the rentier economy framework. The third perspective associates civil society with non-government organisations (NGOs) and private voluntary associations (PVOs). The NGO literature suggests that the legitimation of civil society occurs where governments set the parameters of action in conjunction with donors in a bid to achieve gradual social reform. Previous work on Arab civil society-written from dependency, modernisation and rentier perspectives-views independent groups as unimportant with a sparsely populated public space sitting between the family and state (Crystal, 2001; Krause, 2008). Krause, (2008) expands the theoretical concept of civil society, moving away from dichotomous frameworks that view the "state as an entity completely separated from society" and where the "power struggle against a dominant force is categorised as either resistance or compliance orientated" to take into account religious, social, and political forces.

In other work, Crystal, (2001) used social stratification as a means to comprehend the civil society concept allowing identification of an array of groups as well as the mechanisms that connect independent groups to each other and to those in power. Broken into an economic, social and politically orientated ensemble, Crystal, (2001) classified a number of dimensions that constitute civil society. From an economic point of view, dimensions such as class and sector and the emergence of new middle class are important. Membership of social groups such as tribes or sects, extended family, gender, age and generational changes, are significant. Finally, political groups are important and are identified in terms of those with access to state resources-which includes those with direct access to rulers-and to the bureaucrats and technocrats that work for the state. All these dimensions intertwine in complicated and unknown ways in terms of "how they connect to each other and to those in power (Crystal, 2001, p. 261)". The significance of a broader theoretical civil society concept allows for a deeper approach to the examination of the power and impact of civil society within a critical account of education. 


\section{Arab civil society and higher education}

As stated above, civil societies in the Arab education sector, are traditionally identified with the provision of education services for marginalised members of society. Watkins, (2009) notes that in the last decade, new groups have formed which has led to more active and powerful relationships between civil societies and education, as well as an increase in the power of regional networks. For example, the Arab Network for Literacy and Adult Education participated in the Arab League Summit in 2007. The participation of the network was significant in that this was the first occasion a social issue was on the agenda at a summit meeting. Subsequently, the Arab Network for Literacy and Adult Education was raised to co-author of the Arab states region first report on education as well as acting as the Vice-President of the International Council for Adult Education (ICAE), leading to a strengthening of regional NGO coalitions in the Arab states (Arab Network for Literacy and Adult Education, 2009). While the main focus of the Arab Network for Literacy and Adult Education, (2009) report is related to the Education For All discourse, the issues it raises in relation to civil society partnership and the limitations of the region's legal, social, cultural and economic characteristics are noteworthy. For example, the existence of legal frameworks allowing a wide series of interventions by government, which includes government consent and the approval to set up, as well as high levels of bureaucracy. In relation to cooperation with governments, often declarations of participation and involvement of civil society groups by government is nothing more than a declaration of intent and sometimes is not followed up with tangible results. Central authorities often limit decision making powers of Ministries of Education, leading to a dominance of a few government actors. The development of open and balanced partnerships between civil society and governments is further complicated by a 'needs-based approach' to collaboration linked to education and development issues recognised as requiring immediate attention. In many cases civil society organisations cannot form and act independently of state powers, while there is a lack of legislation at a regional level, limiting the establishment of civil society networks and coalitions (Watkins, 2009).

However, while issues and challenges exist in the field of civil society and education, Lamine, (2010, p. 39) concludes that across the Arab region, including the GCC, there is agreement for cooperation in the field of higher education. The areas of agreement include quality assurance and accreditation at an Arab level; degree equivalence and recognition including an Arab qualifications framework; exchange (of information, expertise, students, study grants); joint programs and projects (Arab protocol on patents and intellectual property); networking and databases. Lamine (2010) notes the establishment of the NGO Arab Network of Quality Assurance in Higher Education (ANQAHE), which works in cooperation with International Network of Quality Assurance in Higher Education (INQAHEE) and in partnership with the Association of Arab Universities (AAU) as well as range of other groups including Arab Organisation for Quality Assurance (AROQA), the Association of Quality Assurance Agencies of the Islamic World (AQAAIW), and the Arab Quality Assurance and Accreditation Network for Education amongst others.

\section{Civilisation analysis as a means to interpret civil society}

If conceptualisations of civil society are orientated in eurocentrism, then civil society and how it is defined in an Arab context has to be studied from within its own social, cultural and political contexts all of which are grounded within a historical trajectory (Armstrong \& Gilson, 2011). The challenges of this viewpoint are threefold. Firstly, it is necessary to define what is understood by culture and society, as they are open to different interpretations derived from various ontological and epistemological positions. Secondly, the dynamics of culture, religion, values and traditions are recognised as converging in complicated ways and 


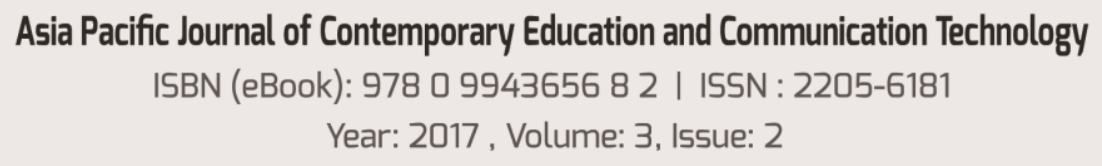

is generally not well understood. In the Arab context, the understanding of cultural and social dynamics is outdated, under-theorised and is considered to be an undervalued area of study (Sholkamy, 2006). If the dynamics of culture, religion, values and traditions are not well understood, it becomes difficult to recognise the full and true extent of the role of global, geo-regional and national institutional structures and dynamics and their impact on civil society or vice versa for example. Thirdly, the cultural problematic of meaning-not in the sense of being restricted to semiotics and the dominant view of world polity theory-remains difficult to explain and outcomes difficult to determine. In order to find and address the social, cultural an political questions-the basis on which Arab culture and society is interpreted-the analyst can engage with civilisation analysis (Arnason, 2003) as an epistemic space. Analysing Arab modernity, culture and societies, using civilisation analysis (CA) as a theoretical framework, offers a means of accessing deeply entrenched sets of meanings and practices allowing for a comparative interpretation of societal differences in education (Dale \& Robertson, 2016).

Civilisation analysis is witnessing a rejuvenation, particularly in the field of sociology. Arjomand \& Tiryakian (2004) note that civilisation analysis originated in the work of Weber, Durkheim and Mauss; a group consisting of Sorokin, Elias and Nelson continued the development which was followed up with the more recent civilisational analysis conceptualisations developed by Huntington, Eisenstadt, and Arnason. The primary claim for the development of a civilisation analysis approach within analysis of civil society and education is that it provides a means of comparison which recognises the characteristics and meaning of "deeper cultural sources of current institutions, practices, and justifications, without which we cannot fully understand current educational institutions, issues and practices" (Dale \& Robertson, 2016). The overarching ambition of using civilisational analysis is therefore grounded in the aim of producing a more complete theory of the characteristics and effects of civilisational forms and legacies.

\section{Alternative paradigms}

While Johann Arnason provides a mechanism of analysing civilisations and modernity, it is necessary to note other notable paradigms that may be useful. Some of these paradigms are limited in terms of the spatial and temporal situation of Arab culture, while it can also be argued are also ultimately lacking in terms of suitability as methodologies that allow comparisons across global education systems. Competing paradigmatic and methodological approaches appropriate for Arab sociology orientated research include Orientalism, Occidentalism, Neopatriarchal Society, Historicism, Foucault's Archaeological Method, Arab Cultural Studies and Modernisation Theory.

Orientalism as a conceptual framework focuses on the appropriation of the Orient through colonialism and imperialism encounters (Said, 1977). Occidentalism, as a framework to study Arab conceptualisation of the West, much of which has been about the idealisation of the western 'Other', 'the desire to become the other or at best become like the other' (Enany, 2006, p. 7). Sharabi, (1988) neopatricarchal society is a concept with multiple applications; a model; an analytical tool; a means of interpretation; and a theory. Sharabi states that ideologically the concept can be used at the macro level of society, state and economy to the micro level of family.

Significant Arab intellectuals such as Adonis, Laroui, \& Al-Jabiri (2011) have discussed in different ways the significance and relationship between Arab subjectivity, history, and modernity (Sheedi, 1997, p. 42). Al-Jabri uses Foucault's Archaeological method to fundamentally question the theory of tradition and history while dismissing "the idea of a unitary Arab reality or singular Arab Islamic tradition (Sheedi, 1997, p. 42)”. Laroui uses 


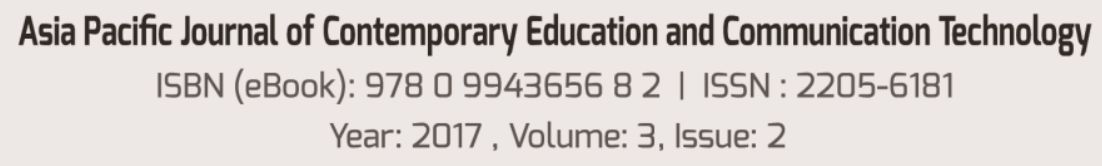

historicism, deeming it to be the most adept measure in determining Arab identity. Pormann, (2013) examines the influence of Graeco-Roman classics on contemporary AraboIslamic culture. Sabry, (2010) suggests that Arab cultural studies, as an episteme, is useful in the pursuit of the present cultural tense of Arab culture, and draws on the work of Al-Jabri and Abu-Lughod. On this note, Abu-Lughod (1963) began a new era in terms of modern Middle East as a field of study, focusing on the Arab world, its intellectual history and history of ideas as opposed to Islam and the larger Ottoman Near East (Khalidi, 2011). Along with Hourani (1983), both their works are impacted by modernisation theory and a set of theories about Westernisation and progress.

\subsection{Civilisation Analysis as a means of unlocking the social,}

\section{cultural and political questions}

Civilisational analysis as a term signifies the amalgamation of theoretical and historical approaches to the comparative study of civilisations with a specific focus on the constitutive patterns and long-term dynamics of civilisations. These fundamental patterns and dynamics are accepted to exist as maco-cultural, macro-social and macro-historical units as well as questions related to how these patterns and dynamics are involved in modern transformations (Arnason, 2009). A 'paradigm in the making' (Arnason, 2009) civilisational analysis has become more accepted as a specific mode of social and historical inquiry, particularly in the new phase that began in the 1970's following the contributions of the Durkheimian school and Max Weber in the first two decades of the twentieth century. The early work of Durkheim and Mauss distinguished civilisations as 'large scale and long term formations which include multiple societies, both contemporary and successive'; this period also coincides with Durkheim's systematic turn towards the sociology of religion (Arnason, 2009, p. 2)'. At the same time, Max Webber's comparative studies were focusing on the major world civilisations and their religious traditions. The importance in educational terms, is that civilisations do matter-particularly in comparative education-where their "traces continue to shape processes and outcomes" (Dale, 2016).By accessing the cultural, political and social questions through civilisational analysis, researchers can determine specific social, cultural and political aspects and in turn consider how they shape processes and outcomes.

Arnason (2004) outlines that his provisional model of defining civilisations is, in the most part, not identifiable with any particular existing version of civilisation theory, but that the components have been thematised-in connection with each other-and form important contributions to the debate. The six aspects of the civilisation analysis paradigm draws on "various lines of argument in sociological theory as well as comparative history (Arnason, 2009, p. 106)". The changing roles and weights of these six thematic foci or "inventory of civilisational components" underline the need for flexible conceptualisation, particularly in relation to variety of historical contexts. The first three components form the internal structures of civilisations, while the remaining three relate to their expansion spatially and temporally. Arnason, (2009) identifies that understanding the distinctive and formative cultural orientations as the most pivotal question of civilisational theory and may give the analyst the foundation to a specific universe of meaning and compares to Eistenstadt's cultural ontologies or visions of cosmic and social order. This cultural problematic or 'constellation of meanings' are of particular importance in terms that understanding and defining the cultural problematic can point to the way in which a civilisation constructs, represents and transforms social order. Therefore, when meaning is combined with the concepts of wealth and power a framework can be formed that allows for theoretical synthesis and comparative enquiry. 


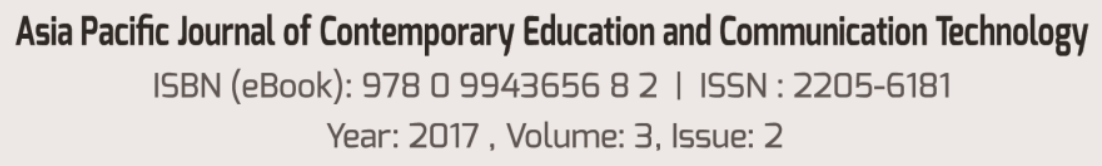

The second aspect of the model-institutional structure and dynamics-is deemed by Arnason to be the least developed part of civilisational analysis and argues that drawing a distinction between cultural, political and economic structures may prove useful, allowing analysis of the civilisational connections between them by drawing on the cultural interpretations of power and wealth and how these interconnected problematics link to both political and economic institutions. Through the cultural interpretation of power, the political sphere is connected to the cultural sphere. The cultural interpretations of power, comparatively speaking allow the analyst to focus on the "integrative, preservative or transformative" aspects (Arnason, 2009, p. 107). In terms of the economic structures and dynamics, Arnason, (2009, p. 108)notes various angles in terms of the analysing the comparative civilisation aspect including modes of accumulation, capacities used to sustain commercial development as well as Braudel's analysis of capitalism (Arnason, 2003), however the overall view is that economic aspects are more difficult to theorise. Arnason suggests that using Braudel's three categories or levels of economic life-material civilisation, domain of circulation and pursuits of profit through trade-allows for ways of investigating civilisation backgrounds. In this context and due to the fact that state power structure is specifically engrained in Braudels concept of capitalism allows for analysis of the interplay between political and economic dynamics.

The third component, while belonging to the institutional dimension, is deemed important enough to warrant a separate discussion and focuses on the concept of dominant world views. While the importance of "formative ideas, texts and elites is not in question (Arnason, 2009, p. 108)". Arnason proposes in his model to treat them as "a derivative and variable aspect of civilisational complexes". Arnason, (2009, p. 107) expresses concern that comparative studies have accepted as standard or authentic, dominant or exclusive world views without considering that these views are often "embodied in canonical texts and represented by cultural elites". These texts-such as scared religious scriptures-and the cultural elites endeavour to "control their interpretations, share power with other elites in varying and unstable ways" and therefore have the ability to shape the characteristics of a civilisation through its central institutions. These first three aspects focus on the internal structure of civilisation, while the remaining three can be identified as traits of civilisation.

Moving to the last three aspects of the model, the visibility of the multi-societal structure (families of societies) is a prime defining feature of civilisations and is the most evident in terms of the macro-formations mentioned above although there are some significant differences between them when considering the major civilisational worlds of pre-modern times such as Mesopotamia and Egyptian civilisation. These 'families of societies' can be thought of as sociocultural frameworks whereby smaller groups (societies) can be more or less autonomous and expand "their variations on shared themes (Arnason, 2003, p. 109)". The importance of this notion of a multi-societal structure is that if multi-societal structures exist, then political fragmentation prevails, with Arnason contending that "political unity of a civilisational area can only be envisaged as a very exceptional state of affairs (p. 109)".

The temporal and spatial meaning of successive generations of society (the multi-societal structure has a temporal and spatial meaning) and the fact that comparative studies need both the concept of a 'multi-epochal civilisation' and a 'multi-civilisational sequence' is the fifth aspect of the model and takes into account the complex factors that as civilisations "transition from one civilisational episode to another",that transition can often "coincide with shifts of the geopolitical and geocultural centres, and interaction with other civilisational sequences (Arnason, 2004, p. 110)" . These factors need to be taken into account in terms of analysing the modern civilisation. Arnason, (2003, p. 304) suggests that this trait of civilisations is one of the least explored in civilisations analysis and is challenging in terms of its complexity. 
The final feature of the model is the regional basis of civilisational distinctions with "historical formation and transformation of civilisations taking place in geographical contexts" with different civilisation patterns occurring. The relationship between civilisation and regional aspects is not simple, taking into account the distinct and varying civilisational patterns, for example the Islamic world. The first Islamic conquests and subsequent formation of Islam as a worldwide religion came about as a result of the annexation of the Nile Oxus region-"the oldest and most central multi-civilisational sphere"-subsequent cultural unification, religious expansion and imperial conquests "led to the Islamisation of more remote regions" which were then "integrated into a supra-regional formation", but still retaining sufficient unique characteristics "to give rise to more or less original variants of the universal model (Arnason, 2004, p. 111)”. On the other hand, enduring multi civilisation constellations exist in the regions such as the Mediterranean, which throughout its history "has been an arena of inter civilisational encounters (Arnason, 2004, p. 111)".

\section{Conclusion}

The intention of using civilisational analysis is to provide a systematic effort directed towards theorising and refining concepts aimed at addressing, in a contextualised and comprehensive fashion, questions related to if and how Arab civil societies have a role in the process of change within Arab and Gulf Cooperation Council (GCC) higher education. It allows questions of power and impact of power to be addressed, looking beyond the traditional dependency, modernisation and rentier perspectives. The six thematic foci of civilisation analysis allows for a deeper analytical approach in order to comprehend the concept and structure of civil society, unlocking the social, cultural an political contexts of Arab civil society. In doing so, civilisation analysis creates a means in which the researcher can recognise and embed meaning to the inter-related aspects of political order and its relationship with social order, how political order and accountability is understood, and it can also address analytical blindness in relation to symbolic and institutional framework of Arab civilisation such as the Islamic Umma and its dynamics. Civilisation analysis, as a theoretical approach, allows for a deeper analytical approach in considering the processes at play in the relationship between education and civil society. 


\section{Asia Pacific Journal of Contemporary Education and Communication Technology

\section{References}

i. $\quad$ Al-Jabri, M., 2011. The Formation of Arab Reason - Text, Tradition and the Construction of Modeni- ty in the Arab World. London: IB Tauris.

ii. Arab Network for Literacy and Adult Education, 2009. The Arab States Region' in P. Watkins (ed)Collective Consultation of NGO's on Education for All - Halfway to 2015 - Civil Society Engagement in Education Policy Dialogue and EFA Process since Dakar 2000 - A Study, UNESCO. London: UNESCO.

iii. Arjomand, S. \& Tiryakian, E., 2004. Introduction in S.A. Arjomand and E.A. Tiryakian (eds) Rethinking Civilizational Analysis. London: Sage Publications.

iv. Armstrong, D. \& Gilson, J., 2009. Introduction - Civil society and international governance. In: R. H. a. W. R. Nasson, ed. World Civilisations and History of Human Development. Oxford: UNESCO, pp. 1-34.

v. Armstrong, D. \& Gilson, J., 2011. Introduction - Civil society and international governance. In: Armstrong, V. Bello, J. Gilson \& D. Spini, eds. Civil Society and International Governance - The role of non-state actors in global and regulatory frameworks. Oxon: Rutledge, pp. 112.

vi. Arnason, J., 2003. Civilizations in Dispute: Historical Questions and Theoretical Traditions. Boston : Bill.

vii. Arnason, J., 2004. Civilization Patterns and Civilizing Processes in S.A. Arjomand and E.A. Tiryakian (eds) Re- thinking Civilizational Analysis. London: Sage Publications.

viii. $\quad$ Arnason, J., 2009. Civilisational Analysis: A paradigm in the making in $R$. Holton and $W R$ Nasson (eds) World Civilisations and History of Human Development. Oxford: UNESCO.

ix. Bardhan, S. \& Wood, R., 2015. The Role of Culture and Technology in Civil Society Promotion in the Middle East: A Case Study Approach. Digest of Middle East Studies, 24(1), pp. 111-138.

x. Carapico, S., 1998. Civil Society in Yemen: The Political Economy of Activism in Modern Arabia. Cambridge: Cambridge University Press.

xi. Crystal, J., 1989. Coalitions in Oil Monarchies: Kuwait and Qatar. Comparatve Politics, 21(2), pp. 427-443.

xii. Crystal, J., 2001. Civil Society in the Arabian Gulf. In: A. Norton, ed. Civil Society In the Middle East (V2). Netherlands: Brill, pp. 259-288.

xiii. Dale, R., 2016. What would it mean for Comparative Education if 'Civilisation (s)' were to be taken seriously. Vancouver, 5 - 10th March. Vancouver, s.n.

xiv. Dale, R. \& Robertson, S., 2016. What would it mean for comparative education if 'civilisation' were to be taken seriously? Vancouver, Canada, 5 - 1oth March Comparative and International Education Society 2016 Annual Conference. Vancouver, CIES.

xv. Eisenstadt, S., 2002. Concluding Remarks: Public Sphere, Civil Society, and Political Dynamics in Islamic Societies. In: M. Hoexter, S. Eisenstadt \& N. Levtzion, eds. Public Sphere in Muslim Society. Albany: State University of New York Press, pp. 139-161.

xvi. Eisenstadt, S. \& Schluchter, W., 1998. Introduction: Paths to Early Modernities - A Comparative View. Daedalus, 127(3), pp. 1-18.

xvii. Enany, E., 2006. Arab Representations of the Occident - East-West Encounters in Arabic Fiction. London and New York: Routledge.

xviii. Hann, C., 1996. Introduction: political society and civil anthropology. In: C. Hann \& E. Dunn, eds. Civil Sciety - Challenging Western Models. London: Routledge, pp. 1-25. 


\section{Asia Pacific Journal of Contemporary Education and Communication Technology \\ ISBN (eBook): 9780994365682 | ISSN : 2205-6181 \\ Year: 2017 , Volume: 3, Issue: 2}

xix. Hourani, A., 1983. Arabic Thought in the Liberal Age 1798 - 1939. Cambridge: Cambridge University Press.

xx. Hourani, A., 2004. Introduction. In: A. Hourani, P. Khoury \& M. Wilson, eds. The Modern Middle East (2nd Ed). London: IB Tauris, pp. 1-22.

xxi. Khalidi, R., 2011. Introduction to this New Edition. In: I. Abu-Lughod, ed. The Arab Rediscovery of Europe - A Study in Cultural Encounters. London: SAQI, pp. 7-14.

xxii. $\quad$ Krause, W., 2008. Women in Civil Society - The State, Islamism and Networks in the UAE. Hampshire: Palgrave Macmillan.

xxiii. $\quad$ Lamine, B., 2010. Towards an Arab Higher Education Space: International Challenges and Social Responsibilities. Beruit: UNESCO Regional Bureau for Education in the Arab States.

xxiv. Patel, S., 2013. Are the Theories of Multiple Modernities Eurocentric? The Problem of Colonialism and its knowledges. In: S. Arjomand \& E. Reis, eds. Worlds of Difference. London: Sage, pp. 40-58.

xxv. Pormann, P., 2013. Classical Scholarship and Arab Modernity. In: S. Humphreys \& R. Wagner, eds. Modernity's Classics. London: Springer, pp. 123-141.

xxvi. Sabry, T., 2010. Cultural Encounters in the Arab World - On Media, the Modern and the Everyday. London: IB Taurus.

xxvii. Said, E., 1977. Orientalism. London: Penguin.

xxviii. Sharabi, H., 1988. Neopatriarchy - A Theory of distorted change in Arab Society. Oxford: Oxford University Press.

xxix. Sheedi, S., 1997. Failure, modernity and the works of Hisham Sharabi: Towards a postcolonial critique of Arab subjectivity. Critique: Critical Middle Eastern Studies, 6(10), pp. 3954 .

xxx. Sholkamy, H., 2006. The frustrations and future of teaching qualitative methods in the Arab world. Anthropology of The Middle East, 1(2), pp. 20-34.

xxxi. Watkins, P., 2009. Introduction. In: P.Watkins, ed. ollective Consultation of NGO's on Education for All - Half- way to 2015 - Civil Society Engagement in Education Policy Dialogue and EFA Process since Dakar 2000 - A Study. s.l.:UNESCO, pp. 7-18. 